\title{
INTERNATIONAL ASTRONOMICAL UNION
}

\section{WORKING RULES}

\section{Introductory comment}

Substantially modified Statutes and Bye-Laws of the International Astronomical Union were accepted at the XXVth General Assembly. The IAU Executive Committee resolved that a Working Rules Committee consisting of Johannes Andersen, Robert Williams, Hans Rickman and Robert Milkey, is charged with the task to update the IAU Working Rules to ensure that they will be in full harmony with the new Statutes and Bye-Laws. A new version of the IAU Working Rules will be submitted for consideration at the forthcoming meeting of the Executive Committee. The Working Rules for the period 2000-2003 are given in the following:

\section{NON-DISCRIMINATION}

1. The International Astronomical Union follows the regulations of (ICSU): The International Council for Science and concurs with article 5 of ICSU Statutes which defines the basic tenets of non-discrimination and of the universality of science:

In pursuing its objectives in respect of the rights and responsibilities of scientists, $I C S U$, as an international non-governmental body, shall observe and actively uphold the principle of the universality of science. This principle entails freedom of association, expression, information, communication and movement in connection with international scientific activities, without any discrimination on the basis of such factors as citizenship, religion, creed, political stance, ethnic origin, race, color, language, age or sex. ICSU shall recognize and respect the independence of the internal science policies of its National Members. ICSU shall not permit any of its activities to be disturbed by statements or actions of a political nature."

Participants in IAU-sponsored activities who feel that they have been subjected to discrimination are urged in the first instance to seek immediate clarification of all aspects of the incident, which may have occurred simply because of misunderstandings due to cultural differences inherent in an international organization such as the IAU. If the attempt to seek c1arification does not prove satisfactory, contact should then be made with the IAU General Secretary who will seek to resolve the issue.

In the last resort, the Chairperson or the Secretary of the ICSU Standing Committee on the Freedom in the Conduct of Science (SCFCS) should be approached. The SCFCS has been created by ICSU in 1963 in order to safeguard the principle of the universality of science and to assist in the solution of specific problems. The SCFCS has, ever since, worked vigorously to ensure that this principle is upheld by providing advice and taking appropriate measures. The Executive Secretary of the SCFCS, Dr. P. Schindler, can be reached at the following address: Hohenbühlstrasse 8, CH 8032 Zürich, Switzerland (Telephone: 411262 2737, Telefax: 411261 1095, e-mail: pschindler@access.ch). 


\section{MEMBERSHIP}

\section{National Membership}

2. Applications of countries for Full or Associate Membership of the Union are examined by the Executive Committee for:

2.a. the adequacy of the category in which the country wishes to be classified;

2.b. the present state and expected development of astronomy in the applying country;

2.c. the degree to which the prospective adhering body is representative of its country's astronomical activity.

3. Applications proposing an adequate annual contribution to the Union shall, with the recommendation of the Executive Committee, be submitted to the General Assembly for decision.

\section{Individual Members}

4. Individuals proposed for Union Membership should, as a rule, be chosen from among astronomers and scientists whose activity is closely linked with astronomy, taking into account:

4.a. the standard of their scientific achievement;

4.b. the extent to which their scientific activity involves research in astronomy;

4.c. their desire to assist in the fulfillment of the aims of the Union.

5. young astronomers should be considered eligible for membership after they have shown their capability (as a rule Ph.D. or equivalent) of and experience (some years of successful activity) in conducting original research.

6. For full time professional astronomers the achievement in astronomy may consist either of original research or of substantial contributions to major observational programs.

7. Others are eligible for membership only if they are making original contributions closely linked with astronomical research.

8. Eight months before an ordinary General Assembly, adhering bodies will be asked to propose new Members. The proposals should reach the General Secretary not later than five months before the first session of the General Assembly. Proposals received after the closing date will only be taken into consideration if the delay is justified by exceptional circumstances.

9. Each proposal shall be prepared separately and signed by the proposer. It should include the name, first names, postal and electronic ad dresses of the candidates, Institute or Observatory, place and date of birth, the University and the year of Ph.D. or equivalent title, present occupation, titles and bibliographic data for two or three of the more important papers or publications, and details, if any, worthy to be considered by the Nominating Committee.

10.a. Pursuant to article 13 of the Statutes, Presidents of Union Divisions or Chairpersons of Working Groups of the Executive Committee wishing to nominate candidates for Membership should address their suggestions to the General Secretary at least nine months before the first session of an ordinary General Assembly. The nominations should contain particulars as in article 9 here above. 
10.b. The General Secretary notifies the appropriate adhering bodies about such suggestions.

11. The General Secretary shall prepare two lists for the Nominating Committee:

11.a. One containing the candidates proposed by the adhering bodies,

11.b. the other containing those suggested by Presidents of Divisions or Chairpersons of Working Groups of the Executive Committee, but not included among the proposals of the adhering bodies.

12. The Nominating Committee prepares the final proposals for Union membership from the two lists as mentioned in article 11 here above.

13. Adhering Bodies should propose the deletion of Members who have left the field of astronomy for other interests, unless they continue to contribute to astronomy. Such proposals should be announced to the Member concerned and to the General Secretary. Individual Members may resign from the Union by written notification of their resignation to the General Secretary.

14. The alphabetical list of Union Members will be published by the General Secretary following each ordinary General Assembly.

\section{COMMISSION MEMBERSHIP}

15. Members of Union Commissions are co-opted by Commissions. The rules governing the procedure of such co-option are drawn up by the Commissions themselves.

16. Commissions should choose, or ap prove of, Commission members taking into account their special interests, in particular their scientific activity in the appropriate fields of research and. their contribution to the work of the Commission. They may:

16.a. invite Union Members to become members of their Commission;

16.b. remove Union members who have not contributed to the work of the Commission;

16.c. accept or reject applications for membership from existing or proposed Union Members;

17. Members may not, as a rule, be members of more than three Commissions.

18. Members may apply for Commission membership by writing to the President of the Commission concerned. Such applications should only be made if the Member is actively engaged in the appropriate field of research and is prepared to contribute to the work of the Commission.

19. Members of Commissions may resign from a Commission by writing to its President.

20. Adhering Bodies, in sending in their proposals for new Members, may also suggest one Commission for each candidate.

21. The General Secretary will record and analyze the lists of members of Commissions. If necessary, the General Secretary will try to resolve any outstanding anomalies. 
22. The list of Commission members will be published by the General Secretary in the Transactions of each ordinary General Assembly.

\section{CONSULTANTS}

23. Eligible as Consultants are non-astronomers in a position to further the progress of astronomy.

24. Proposals of Commissions for the approval of consultants should, as a rule, reach the General Secretary not later than five months before the first session of an ordinary General Assembly.

25. The General Secretary shall prepare a list of those proposed for admission as consultants and submit it to the Executive Committee for approval.

26. The Administrative Office will maintain an alphabetical list of consultants.

27. Consultants may participate in the meetings of the Union. They may have voting right in the respective Commission. They receive, free of charge, the Information Bulletin of the Union.

\section{SCIENTIFIC MEETINGS}

28. The General Secretary shall publish rules for scientific meetings organized or sponsored by the Union.

\section{PUBLICATIONS}

29. The publications of the International Astronomical Union, approved in the budget by the General Assembly, are prepared by the Administrative Office of the Union.

30. Commissions of the Union may, with the approval of the Executive Committee, issue their publications independently.

31. The distribution of publications of the Union is decided, on the proposal of the General Secretary, by the Executive Committee.

32. Members may purchase the publications of the Union at reduced prices.

\section{EXTERNAL CONTACTS}

33. No dealings with third parties, attributable to the Union, shall be undertaken by any Member of the Union except on the authority of the General Secretary.

34. Representatives of the Union in other bodies, especially in the ICSU General Assembly and Scientific Committees and Programmes, shall be appointed by the Executive Committee. Nominations are sought from Presidents of appropriate Commissions.

35. Expenses incurred by Representatives of the Union in other bodies will be reimbursed at the discretion of the General Secretary, within the provisions of the Budget Estimate adopted by the General Assembly. Representatives are required to obtain prior approval of the General Secretary before incurring such expenses.

\section{GENERAL ASSEMBLIES}

36. The General Secretary distributes the budget prepared by the Executive Committee to National or other appropriate Committees of Astronomy and/or Adhering Organizations for comments eight months before the General Assembly. 
37. The decisions and recommendations of the Union on scientific and organizational matters are expressed in its Resolutions. Resolutions are proposed, evaluated, and approved according to the following guidelines:

37.a. Resolutions fall in three categories:

A: Resolutions, proposed by Adhering Bodies or by the Executive Committee. B: Resolutions, proposed by Divisions or Commissions not attached to a Division and adopted by the General Assembly,

C: Resolutions, adopted by Divisions or Commissions, but not presented to the General Assembly.

Resolutions proposed by Working Groups of the Executive Committee, of Divisions. or of Commissions not attached to a Division, shall be submitted to the parent bodies of these Working Groups for evaluation and approval as for other Resolutions proposed by these bodies.

37.b Resolutions should be submitted on standard forms appropriate to Resolutions of type $\mathbf{A}, \mathbf{B}$, and $\mathbf{C}$, respectively. These forms are available from the IAU Secretariat.

37.c. Resolutions of type A must be placed on the Agenda of the General Assembly and must be submitted to the General Secretary at lea st six months prior to the beginning of the General Assembly. Resolutions of type A or $\mathbf{B}$ which have implications for the budget of the Union must be submitted to the General Secretary nine months in advance in order to be considered by the General Assembly.

All other Resolutions of type $\mathbf{B}$ must be submitted to the General Secretary three months before the beginning of the General Assembly.

37.d. In truly exceptional cases the Executive Committee may consider accepting late proposals for resolutions of type $\mathbf{B}$.

37.e. At its second session, each General Assembly appoints "a Resolutions Committee consisting of five members of the Union, one of whom shouid be a member of the Executive Committee. The Resolutions Committee remains in office until the end of the following General Assembly.

37.f. The Resolutions Committee will examine the content, wording, and implications of all resolutions of types $\mathrm{A}$ and $\mathrm{B}$ to be presented to the second session of the General Assembly. In particular, it will ad dress the following points:

$i$. Suitability of the subject for an IAU Resolution,

ii. Correct and unambiguous wording,

iii. Consistency with previous IAU Resolutions.

The Resolutions Committee may refer a Resolution back to the proposers for reconsideration or withdrawal, but can neither withdraw nor modify the substance of a Resolution on its own initiative. The Resolutions Committee will notify the Executive Committee of any perceived problems with the substance of a proposed Resolution.

37.g. The Executive Committee will examine the substance and implications of all Resolutions proposed for adoption by the General Assembly (types A and B). The Resolutions Committee presents the proposals with the recommendations of the Executive Committee to the second session of the General Assembly for approval. 
37.h. Resolutions of type $\mathbf{C}$ have force only within the Commission or Division of origin.

\section{WORKING GROUPS}

38. The Executive Committee and the Divisions and Commissions may set up Working Groups for special tasks. Working Groups established by Divisions and Commissions have to be approved by the Executive Committee. All Working Groups are established initially for a period of three years. Before each General Assembly the Divisions and Commissions shall inform the Executive Committee which Working Groups are to be retained for the next 3-year period and which Working Groups are to be dissolved. 